\title{
Aphid Acquisition and Cellular Transport of Potato leafroll virus-like Particles Lacking P5 Readthrough Protein
}

\author{
F. E. Gildow, B. Reavy, M. A. Mayo, G. H. Duncan, J. A. T. Woodford, J. W. Lamb, and R. T. Hay
}

First author: Department of Plant Pathology, Buckhout Laboratory, Pennsylvania State University, University Park 16802; second through fifth authors: Scottish Crop Research Institute, Invergowrie, Dundee DD2 5DA, United Kingdom; sixth and seventh authors: School of Biological and Medical Sciences, BMS Building, University of St. Andrews KY16 9ST, United Kingdom. Accepted for publication 5 July 2000.

\begin{abstract}
Gildow, F. E., Reavy, B., Mayo, M. A., Duncan, G. H., Woodford, J. A. T., Lamb, J. W., and Hay, R. T. 2000. Aphid acquisition and cellular transport of Potato leafroll virus-like particles lacking P5 readthrough protein. Phytopathology 90:1153-1161.

Lepidopteran cells (Spodoptera frugiperda) produced isometric viruslike particles (VLP) when infected with a recombinant baculovirus Ac61 that contained the Potato leafroll virus (PLRV) coat protein gene modified with an N-terminal histidine tag (P3-6H). Cells infected with AcFL, a recombinant baculovirus that expressed cDNA copies of the PLRV

the FL particles were morphologically indistinguishable from particles of PLRV despite the fact that they lacked the P5 readthrough protein present in wild-type PLRV. When aphids (Myzus persicae) were fed on, or injected with, purified PLRV, or VLP of either type (FL or P3-6H) and examined by electron microscopy, no differences were observed among treatments for particle endocytosis, transcellular transport, or exocytosis at the aphid midgut or accessory salivary glands. Particles were observed in the salivary canals and in the salivary duct leading out of the aphid. These results suggest that P5 readthrough protein of PLRV may not be essential for cellular transport of virus through aphid vectors.
\end{abstract} genome RNA, did not produce virus-like particles (VLP). In cell lines doubly infected with Ac61 and AcFL, VLP were formed that contained PLRV-RNA packaged in P3-6H coat protein (FL). Both the P3-6H and
Additional keywords: circulative transmission, Luteoviridae, Polerovirus, vector specificity.
Potato leafroll virus (PLRV; family Luteoviridae, genus Polerovirus) has icosahedral nonenveloped particles approximately $25-\mathrm{nm}$ in diameter that are transmitted in a nonpropagative, circulative manner by some species of aphids $(16,30)$. Evidence suggests that vector-specificity is determined by receptor-mediated endocytosis and exocytosis at the aphid midgut epithelium and at the accessory salivary glands $(8,9)$. Receptor recognition sites on PLRV particles that could regulate endocytotic receptor-ligand binding and site-specific transcellular transport have not yet been identified. The PLRV ssRNA genome $(5.9 \mathrm{~kb})$ contains six open reading frames (ORF). Open reading frames 0,1 , and 2 at the $5^{\prime}$ end code for nonstructural proteins associated with replication (ORF1 and ORF2) or possibly symptom expression (ORF0) (16). Open reading frame four is internal to ORF3 and codes for a nonstructural $17-\mathrm{kDa}$ protein. The PLRV capsid consists of two structural proteins, a $23-\mathrm{kDa}$ coat protein (P3) encoded by ORF3 and a 56-kDa readthrough protein (P5), which results from readthrough of the amber stop codon of ORF3 and continued translation into ORF5 (1). PLRV particles contain mainly P3, with lesser amounts of P5. The ratio of P3 to P5 is unknown for PLRV. For Barley yellow dwarf virus-PAV (BYDVPAV), P5 was estimated to comprise up to $10 \%$ of the protein in virus particles (5).

Serological studies of several members of the Luteoviridae verified the presence of P5 protein exposed on the virus capsid surface $(4,17,25,28,31)$. Results of experiments with mutant clones that did not express P5 suggested that P5 was not essential for assembly of the virus particles $(3,5,19,22)$. However, the particles that lacked P5, produced either in protoplasts inoculated with mutant

Corresponding author: F. E. Gildow; E-mail address: feg2@psu.edu

Publication no. P-2000-0803-02R

(C) 2000 The American Phytopathological Society
cDNA (3) or in plants agroinoculated with mutant sequences in Ti plasmids (2), could not be transmitted to host plants by using aphid vectors. Based on these observations, it was supposed that P5 played an important role in the virus particle recognition thought to regulate aphid transmission. However, these experiments were not designed to differentiate between the ability of the aphid to deliver the virus to the plant and the ability of the virus to infect the plant once inoculated. The function of P5 is still unknown. Genomic RNA from particles of BYDV-PAV lacking P5 were detected by PCR analysis in the hemocoel of aphids acquiring particles following feedings on artificial membranes, suggesting that P5 is not essential for BYDV-PAV transcellular transport into the aphid hemocoel (3). In addition, the carboxy-terminal sequence of the BYDV-PAV readthrough protein was not required for aphid transmission (29). A role has been proposed for P5 protein in protecting the capsid from immunodetection and destruction in the aphid hemocoel $(6,25)$. Evidence indicates that GroEL (= Symbionin), molecular chaperonin proteins produced by endosymbiotic bacteria in aphids, bind specifically to P5 capsid proteins. GroEL may protect the virus from protease, or mask the virus from elimination by hemocyte phagocytosis, or function to alter the virus protein structure and thus aid transmission.

A recombinant baculovirus (Ac61) was recently described that contained cDNA encoding a variant (P3-6H) of PLRV ORF3 with an N-terminal histidine-rich tract (MHHHHHHGDDDDKDA MG) before the first methionine of the coat protein (14). In lepidopteran cell lines inoculated with Ac61, P3-6H assembled into stable virus-like particles (P3-6H-VLP) that were morphologically indistinguishable from those of PLRV, but contained only insect host cell RNA and not PLRV sequences from ORF3. Here we describe the production of a second PLRV particle type (FL-VLP) that consists of P3-6H protein encapsidating PLRVspecific genomic RNA. The primary objective of this study was to determine if the PLRV-like particles that lacked P5 could circulate 
through the bodies of aphid vectors in the same way as PLRV particles. Secondary objectives were to determine if the particles lacking P5 were stable in the aphid hemocoel and if the cloned FL-VLP were infectious if transmitted through aphids.

\section{MATERIALS AND METHODS}

Aphid clones and virus strain. Virus-free stock colonies of the green peach aphid, Myzus persicae (Sulzer), were reared on caged turnips, in environmental growth rooms at $20^{\circ} \mathrm{C}$ with a 18 -h photoperiod. The aphid clones used were designated MP1 and L87 and each was an efficient vector of PLRV in transmission tests (13). The PLRV isolate used was C1 derived from strain 1 (15), and has been characterized for aphid transmissibility (13). Virus was propagated in Physalis floridana maintained in an aphid-free greenhouse. Virus purification involved enzyme maceration of plant tissues, polyethylene glycol precipitation, chloroform-butanol clarification, and sucrose density gradient centrifugation, as previously described (15).

Baculovirus methods. Production of recombinant PLRV-like nucleocapsids in a baculovirus system was as described by Lamb et al. (14). Two constructs were used. One (Ac61) contained the PLRV coat protein gene plus sequence encoding an additional 17 amino acid histidine-rich tag at the $\mathrm{N}$ terminus (P3-6H), and the other (AcFL) produced transcript equivalent to the PLRV genome. The full length cDNA copy of PLRV was assembled from cDNA clones produced during sequencing of the PLRV genome (15) and from an infectious cDNA copy of the PLRV genome in a plant transformation vector, pBNUP110 (7). Cloned and amplified DNA of each construct was cotransfected with Bsu 361-cleaved AcRP23lacZ viral DNA into Spodoptera frugiperda cells (Sf9). Recombinant baculoviruses were plaque-purified and analyzed for expression of each of the two inserts as described by Watson and Hay (32).

Purification of virus-like particles. Methods for purification of PLRV-like VLP from lepidopteran cell lines infected with recombinant NPV were similar to methods previously described (14). Briefly, approximately two to four grams of cells from $500-\mathrm{ml}$ cultures was homogenized in $40 \mathrm{ml}$ of $0.4 \mathrm{M} \mathrm{NaCl}$ in $0.1 \mathrm{M}$ sodium citrate buffer $(\mathrm{pH}$ 6). The extract was clarified by low speed centrifugation at $6,000 \times g$ for $15 \mathrm{~min}$ at $10^{\circ} \mathrm{C}$, and VLP were recovered by centrifugation at $200,000 \times g$ for $2.5 \mathrm{~h}$. Chloroform clarification followed by polyethylene glycol precipitation before the final pelleting was sometimes used, but had little affect on the yield or purity of the VLP. Pellets were resuspended overnight in $2 \mathrm{ml}$ of $0.05 \mathrm{M}$ citrate buffer ( $\mathrm{pH} \mathrm{6)}$. VLP preparations were centrifuged through 10 to $40 \%$ sucrose gradients in $0.02 \mathrm{M}$ phosphate buffer for $75 \mathrm{~min}$ at $200,000 \times g$ in a SW50.1 rotor (Beckman Instruments Inc., Palo Alto, CA) at $10^{\circ} \mathrm{C}$. All fractions from the first sucrose gradient had very high optical densities at $260 \mathrm{~nm}$. Therefore, gradients were fractionated into $0.4 \mathrm{ml}$ fractions and each fraction was examined by immunospecific electron microscopy (ISEM) (23) and enzyme-linked immunosorbent assay (ELISA) with polyclonal anti-PLRV antisera to identify fractions rich in PLRV-like particles. These fractions were pooled, pelleted at $250,000 \times g$ for $1.5 \mathrm{~h}$ in a $75 \mathrm{Ti}$ rotor (Beckman Instruments Inc.), and centrifuged through a second sucrose gradient. Visible peaks in UV absorbance at 260 $\mathrm{nm}$ allowed collection of virus or VLP. Particles of Arabis mosaic virus (ArMV; S20, $\mathrm{w}=53,93$, and 120) and PLRV-C1 $(\mathrm{S} 20, \mathrm{w}=$ 115) were used as controls in sucrose gradients to estimate sedimentation velocity. The resulting fractions were then pelleted as described above, resuspended in $0.02 \mathrm{M}$ phosphate buffer ( $\mathrm{pH} 7)$, and stored at $-80^{\circ} \mathrm{C}$.

Protein characterization of VLP. The protein composition of VLP was assessed as described by Lamb et al. (14). SDS-PAGE followed by western blotting was used to identify the presence of PLRV coat protein (P3) and readthrough protein (P5) in density gradient purified nucleocapsids. An anti-PLRV specific monoclonal antibody (SCR3) specific for epitopes on P3 was used to detect the coat protein (24). An anti-PLRV polyclonal antibody was used to detect both P3 and P5. The histidine tag on purified recombinant particles was detected with alkaline phosphatase conjugated to nitrilotriacetic acid-nickel on nitrocellulose blots (14).

Northern blotting. RNA was extracted from infected insect cells using a guanidinium thiocyanate-based reagent (RNA Isolater, Sigma-Genosys, Cambridge, UK), from infected plant material by the method of Verwoerd et al. (27), and from purified VLP by proteinase $\mathrm{K}$ digestion followed by phenol extraction and ethanol precipitation. RNA species were denatured with formamide/formaldehyde, separated on agarose/formaldehyde gels, transferred to a nylon membrane (Boehringer GmbH, Mannheim, Germany) and probed as described by Webster and Barker (33). The probe used was a digoxigenin-labeled PCR fragment corresponding to a fragment of the PLRV CP gene from nucleotides 3791 through 4327 (18).

Aphid treatments. For membrane acquisition of virus or VLP, aphids were given 24-h acquisition feedings on purified preparations containing approximately $100 \mu \mathrm{g} / \mathrm{ml}$ of PLRV-C1, FL-VLP, or P3-6H-VLP, suspended in $20 \%$ sucrose in $0.01 \mathrm{M}$ phosphate buffer. Aphids fed only on $20 \%$ sucrose or on aphid nontransmitted ArMV were used as controls. Following the 24-h acquisition feeding, aphids were transferred to detached turnip leaves and allowed to feed on the leaves for an additional $24 \mathrm{~h}$. For microinjection, aphids were anaesthetized with a flow of carbon dioxide across the stage of a binocular dissecting microscope and injected with 1 to $2 \mathrm{ng}$ of virus or VLP. Inoculum concentrations were based on UV absorbance at $260 \mathrm{~nm}$ and comparative particle counts by ISEM. Following the acquisition feed or injection, aphids were given a 24-h feed on detached turnip leaves at room temperature and then either placed on $P$. floridana seedlings for transmission bioassay or fixed for electron microscopy. For immunolabeling of virus in vivo, aphids were microinjected with approximately $1 \mathrm{ng}$ of anti-PLRV polyclonal $\mathrm{IgG}$ per aphid, allowed a $2 \mathrm{~h}$ feed on turnip leaves and then microinjected with approximately $0.02 \mu \mathrm{l}$ of ferritin-conjugated goat anti-rabbit IgG diluted 1:20 in 0.01 M phosphate buffer. Antibody-injected aphids were allowed $2 \mathrm{~h}$ feeds on turnip and then fixed for EM.

Infectivity assays. To test for virus transmission and infectivity, aphids were placed in groups of three on individually caged $P$. floridana seedlings for 3-day inoculation feedings. Following the inoculation feeding, the cages were removed and the seedlings were fumigated overnight with nicotine to kill the aphids. The seedlings were then maintained in an aphid-free greenhouse for one month and observed each week for symptoms. Once positive control plants showed obvious dwarfing, yellowing, and leafroll symptoms, all plants were then tested by DAS-ELISA with antiPLRV polyclonal IgG for PLRV infection. Healthy and PLRVinfected $P$. floridana were maintained as controls for each ELISA test. To test for infectivity in vitro, protoplasts were isolated from Nicotianae tabacum cv. Xanthi and inoculated with PLRV or VLP using poly-L-ornithine as described by Miller and Mayo (18). Protoplast infection was assessed by immunofluorescent microscopy with FITC-conjugated antibodies to PLRV and by ELISA. Uninoculated protoplasts treated in parallel were used as controls.

Electron microscopy. Aphids were fixed for EM in $1 \%$ formaldehyde, $2 \%$ glutaraldehyde, in $0.02 \mathrm{M}$ sodium cacodylate buffer ( $\mathrm{pH} 7.4$ ) containing $10 \mathrm{mM} \mathrm{CaCl}_{2}$ and $0.05 \%$ sodium azide (12). Aphids were immersed in the fixative and bisected with a razor blade, then transferred to fresh fixative at $4{ }^{\circ} \mathrm{C}$ and incubated overnight. Following post-fixation in $1 \%$ osmium tetroxide, block staining in $2 \%$ aqueous uranyl acetate, and dehydration in acetone, aphids were embedded in a mixture of Polybed 812-Araldite plastic (Electron Microscopy Sciences, Ft. Washington, PA). Silvergray sections approximately $70-\mathrm{nm}$ thick were contrasted for $45 \mathrm{~min}$ in $2 \%$ uranyl acetate in $10 \%$ isobutanol and for $15 \mathrm{~min}$ in $0.4 \%$ 
lead citrate. Grids were viewed on JOEL 1200 TEMs (JOEL Inc., Peabody, MA) at the Scottish Crop Research Institute and at the Electron Microscope Facility for the Life Sciences in the Biotechnology Institute at Pennsylvania State University.

\section{RESULTS}

Recombinant particle characterization. When Sf9 cells were inoculated with Ac61, expressed P3-6H protein formed 25-nm diameter isometric particles (VLP) that were morphologically and serologically indistinguishable from PLRV, but did not contain PLRV-RNA transcripts (14). In this study, PLRV-RNA transcripts of $\approx 6 \mathrm{~kb}$, corresponding to the size of PLRV genomic RNA, and a smaller species of approximately $5.6 \mathrm{~kb}$ were detected by northern blotting in Sf9 cells $48 \mathrm{~h}$ after inoculation with AcNPV containing the PLRV-FL insert (AcFL; Fig. 1A). No RNA species corresponding in size to the PLRV subgenomic RNA that is found in infected cells was produced and neither the P3 nor P5 structural proteins were detected in extracts of infected cells examined by SDS-PAGE followed by immunoblotting, and no particles were formed. When cells were doubly inoculated with Ac61 and AcFL, FL-VLP were produced that consisted of RNA transcripts produced from AcFL packaged in the P3-6H protein. These FL-VLP were also 25-nm in diameter and were indistinguishable from particles of PLRV in sedimentation properties, in negatively stained electron microscope samples, by ISEM, and by ELISA tests. The FL-VLP reacted with nickel-bound nitrilotriacetic acid, indicating the presence of the histidine-tagged $\mathrm{P} 3-6 \mathrm{H}$ coat protein. The results of RNA electrophoresis in agarose gels and northern blot analysis indicated that FL-VLP contained the 5.6-kb PLRVRNA transcript that was slightly smaller than the PLRV genomic RNA (Fig. 1B).

Ultrastructure of midgut acquisition. The acquisition and transport of P3-6H and FL-VLP through the gut and salivary cells of aphids was compared to that of purified PLRV in $M$. persicae. Ultrastructural observations of aphid tissues normally associated with PLRV transmission indicated no differences among treatments (Table 1). All three particle types were acquired into the hemocoel only through the posterior midgut (Fig. 2A), as described by Garret et al. (8). Neither PLRV particles nor VLP were acquired by cells of the anterior midgut (stomach) or through the hindgut, as has been described for some other luteoviruses $(10,11)$. Following acquisition into the hemocoel, all three particle types were observed concentrated at the accessory salivary gland (Fig. 2B). No particles were observed associated with the principle salivary gland, tracheal connective tissue, optic lobe or subesophageal ganglion nerve tissue, or stylet retractor muscle tissue adjacent to the accessory gland.

Following acquisition feedings through Parafilm membranes on purified PLRV particles or VLP, aphids were examined to determine if the absence of the P5 readthrough protein from the VLP had altered the ability of the particles to be endocytosed into the midgut, to be transported transcellularly, or to be exocytosed into the hemocoel. VLP were observed in the posterior midgut associated with membrane structures indicative of endocytosis and transcellular transport $(9,10,20)$ in a manner identical to that of wildtype PLRV (8). For example, recombinant particles in the midgut lumen were consistently observed attached to the surface of the apical plasmalemma and associated with coated pits indicative of endocytosis (Fig. 3A). Within the cytoplasm, particles were observed in endosomal vesicles and in the process of being packaged into tubular vesicles from endosomes (Fig. 3B and C). Near the basal end of the midgut cells facing the hemocoel, particles were only observed in small clusters of tubular vesicles (Fig. 3D). Because particles in all treatments were observed to concentrate at the accessory salivary gland following membrane feeding, no effort was made to quantitate particle acquisition at the midgut. Although the number of particles per cell was not quantitated,
PLRV, P3-6H, and FL particles were consistently observed in equivalent densities in coated vesicles, endosomes, and tubular vesicles.

Particle stability in the hemocoel. Intact isometric particles were observed embedded in the accessory salivary gland basal lamina (Fig. 4A through D) and in the pericellular space between the basal lamina and the basal plasmalemma following membrane acquisition or microinjection of PLRV and the P5 minus P3-6H and FL particles. Aphids were fixed for EM observations $48 \mathrm{~h}$ following initiation of the acquisition feeding and following a 24-h inoculation feeding on leaf tissues. Microinjected aphids were fixed $24 \mathrm{~h}$ after injection during which time aphids fed on leaf tissue. Normal appearing particles were observed exterior to the salivary gland in 8 of 8 aphids examined in both the PLRV and FL treatments, and in 15 of 15 aphids in the P3-6H treatment when fed on purified particles (Table 1, Experiments 1 and 2). Structural evidence of particle degradation was not observed in any treatment, and particles retained the ability to penetrate the basal lamina and to be endocytosed into the salivary gland. Similar results occurred with microinjected treatments (Table 1, Experiment 3). Particles on the surface of the salivary basal lamina, in the pericellular space, intracellularly in transport vesicles (Fig. 5A and B), and in the salivary duct (Fig. 5C and D) did not show visible evidence of attachment of Buchnera GroEL complexes, which are large enough to be seen by $\operatorname{EM}(6,25)$.

Ultrastructure of salivary gland transcellular transport. To determine if the presence of the hexahistidine tag on the P3 coat protein or the absence of the $\mathrm{P} 5$ readthrough protein influenced the abilities of the P3-6H or FL-VLP to penetrate the salivary basal lamina or to be endocytosed into salivary cells, aphids were allowed to acquire purified particles by feeding through mem-

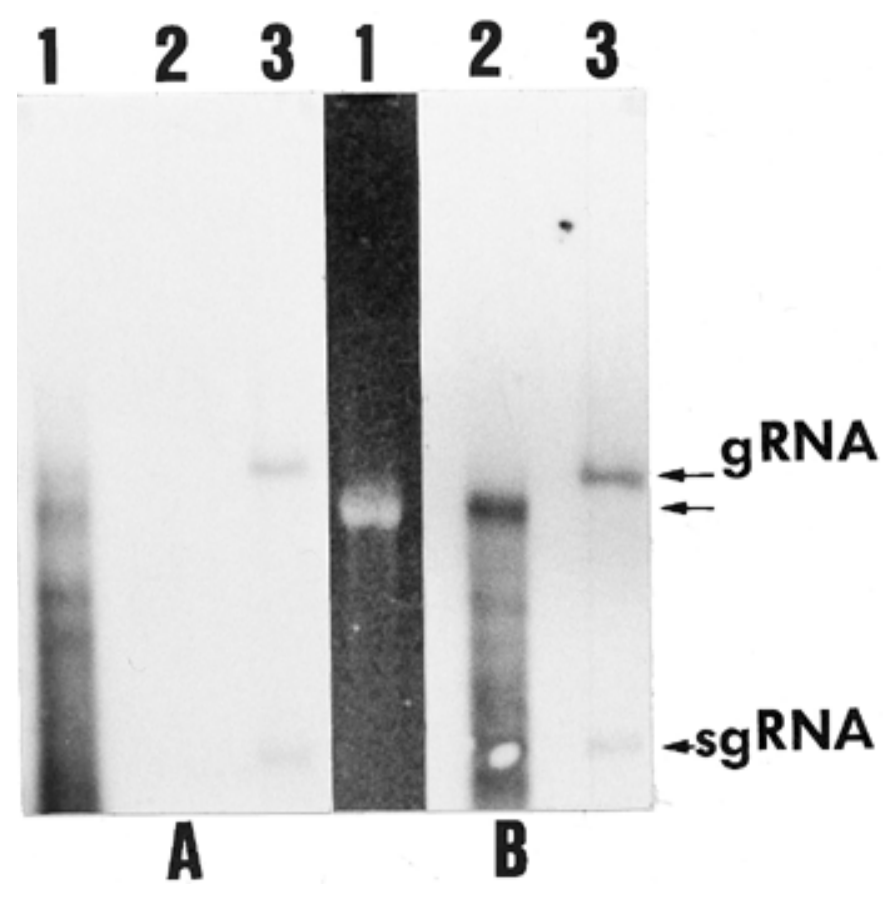

Fig. 1. A, Northern blot analysis of Potato leafroll virus (PLRV) RNA species produced in AcFL-infected cells and detected by a PCR probe from the PLRV coat protein (CP) gene (nt 3791-4327). RNA was extracted from AcFL-infected Sf9 cells (lane 1) or from uninfected Sf9 cells (lane 2) at $48 \mathrm{~h}$ postinfection. RNA was extracted from PLRV-infected plant tissue as a control (lane 3). The positions of the PLRV genomic (g) and subgenomic (sg) RNA species produced in PLRV-infected plant tissues are indicated. B, RNA isolated from purified VLP (unlabeled arrow). The RNA species extracted from FL-VLP and detected by ethidium bromide staining after electrophoresis (lane 1). The RNA species extracted from FL-VLP and detected by probing with the CP gene probe after electrophoresis (lane 2). The PLRVspecific RNA species produced in infected plant tissue (lane 3) detected by electrophoresis and probing as for lane 2 . 
branes or were microinjected with particles directly into the hemocoel. No differences in location of particles in aphid tissues or in particle-membrane interactions associated with endocytosis, transcellular transport, and exocytosis could be detected among PLRV and P3-6H or FL-VLP when acquired by feeding or by microinjection. Both P3-6H and FL particles penetrated specifically into the basal lamina surrounding the accessory salivary gland, similar to PLRV; and did not attach to basal lamina of adjacent muscle or nerve tissues (Fig. 4A through D). Concentrations of PLRV and the VLP in the salivary basal lamina varied from 5 to 30 particles per $10 \mu \mathrm{m}$ length of basal lamina among individual aphids and no differences among treatments were detected. Particles of all three types penetrated through the basal lamina and moved deep into basal plasmalemma invaginations or cisternae where they were observed closely appressed to the cell membrane (Fig. 4B). Occasionally, particles of all three types were seen at the basal cell membrane in coated pits (Fig. 4C) and coated vesicles (Fig. 4D) indicative of endocytosis into the cytoplasm. Once inside the accessory salivary glands, VLP were often observed near the microvilli-lined salivary canals lined by the apical plasmalemma. At this location, VLP or virus particles were observed in linear beadlike arrays in tubular vesicles (Fig. $5 \mathrm{~A}$ ), in coated vesicles, and free in the canal lumen. The detection of VLP in coated pits fused to the canal membrane (Fig. 5B) suggested an exocytotic pathway out of the salivary gland. When aphids were injected with anti-PLRV IgG before fixation for EM, recombinant particles were observed to aggregate into readily detectable clumps in the lumen of the salivary duct leading out of

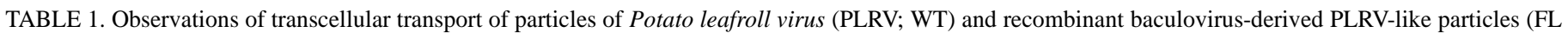

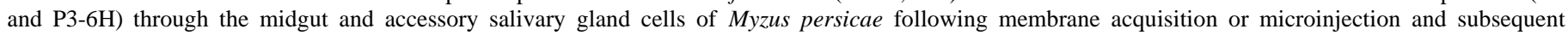
transmission bioassays on Physalis floridana ${ }^{\text {a }}$

\begin{tabular}{|c|c|c|c|c|c|c|c|c|c|}
\hline \multirow[b]{2}{*}{ Experiment } & \multicolumn{3}{|c|}{ Midgut } & \multicolumn{3}{|c|}{ Accessory salivary gland } & \multicolumn{3}{|c|}{$\%$ Infection $^{\mathrm{b}}$} \\
\hline & WT & FL & P3-6H & WT & FL & P3-6H & WT & FL & P3-6H \\
\hline 1 & $4 / 4$ & $4 / 4$ & $2 / 5$ & $4 / 4$ & $4 / 4$ & $6 / 6$ & 90 & 0 & 0 \\
\hline 2 & $8 / 8$ & $8 / 8$ & $3 / 7$ & $4 / 4$ & $4 / 4$ & $9 / 9$ & 40 & 0 & 0 \\
\hline $3^{c}$ & nd & nd & nd & $4 / 4$ & $4 / 4$ & $4 / 5$ & 75 & 0 & 0 \\
\hline Total number ${ }^{\mathrm{d}}$ & $12 / 12$ & $12 / 12$ & $5 / 12$ & $12 / 12$ & $12 / 12$ & $19 / 20$ & 68 & 0 & 0 \\
\hline
\end{tabular}

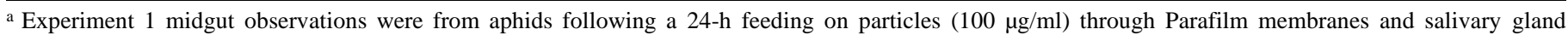
observations were from aphids microinjected with $1 \mathrm{ng}$ of particles. All Experiment 2 observations were from membrane-fed aphids. All Experiment 3 observations were from microinjected aphids. The PLRV (WT) isolate was C1(12). The P3-6H and FL-VLP consisted of PLRV structural coat protein (P3) modified with an N-terminal histidine sequence $(6 \mathrm{H})$ and lacked the structural readthrough protein (13).

b Percentage of 10 to 12 plants infected following a 5-day inoculation feeding by 3 aphids per plant. Infection verified by ELISA 4-weeks postinoculation.

c Not done.

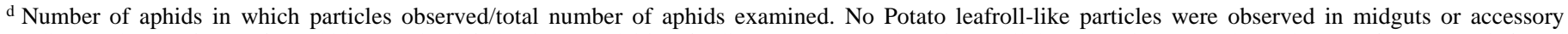
salivary glands of any of 6 aphids examined following acquisition feedings on sucrose done in parallel as negative controls, and none of 12 plants infested with 36 aphids that fed only on sucrose became infected.
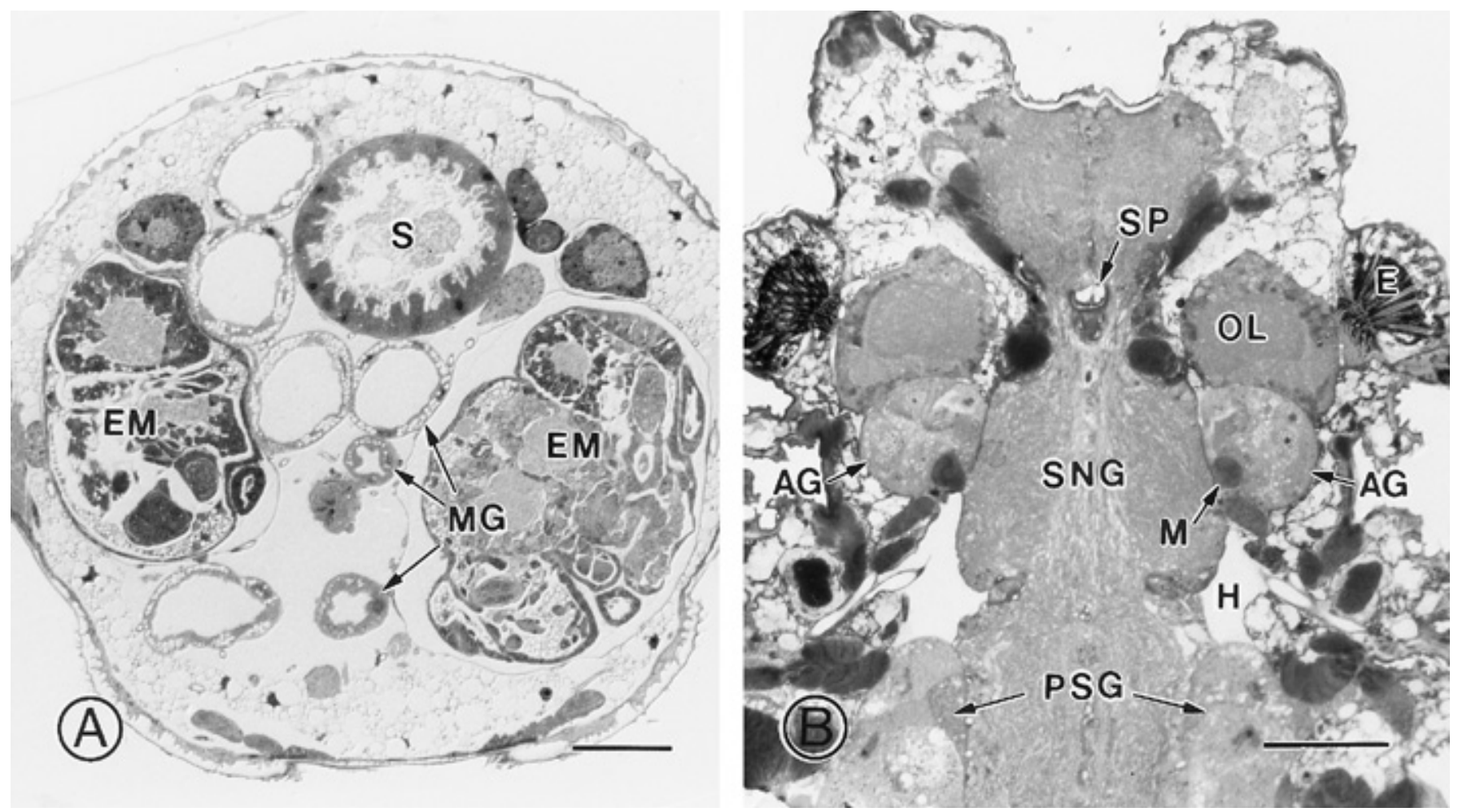

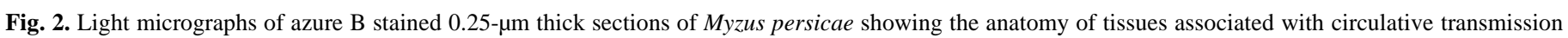

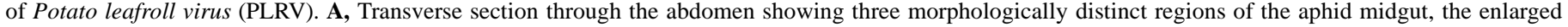

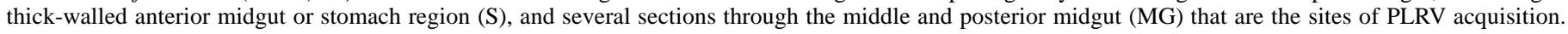

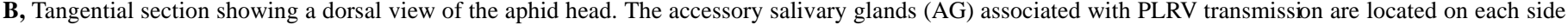

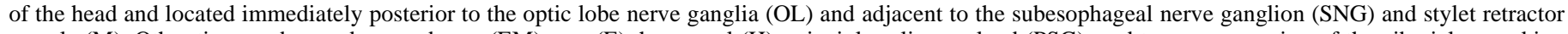

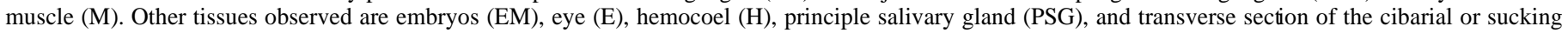
pump (SP). Bar $=100 \mathrm{~nm}$. 
the three aphids examined (Fig. 5C and D). Similar aggregations of particles were not observed in control aphids injected with buffer. The observed ultrastructural associations described above indicated that P5-minus particles of P3-6H-VLP and FL-VLP were transported through the aphids.

Correlation of ultrastructure and transmission. Results of three experiments with different particle preparations, different clones of $M$. persicae, and conducted over a 2-year period gave similar results (Table 1). In two experiments involving membrane acquisition, PLRV particles and FL-VLP were consistently observed in the midgut of all the aphids examined. P3-6H-VLP were observed in fewer aphid midguts, but it was clear that P3-6H-VLP were efficiently acquired into the hemocoel because the VLP were consistently observed in high concentrations at the salivary gland
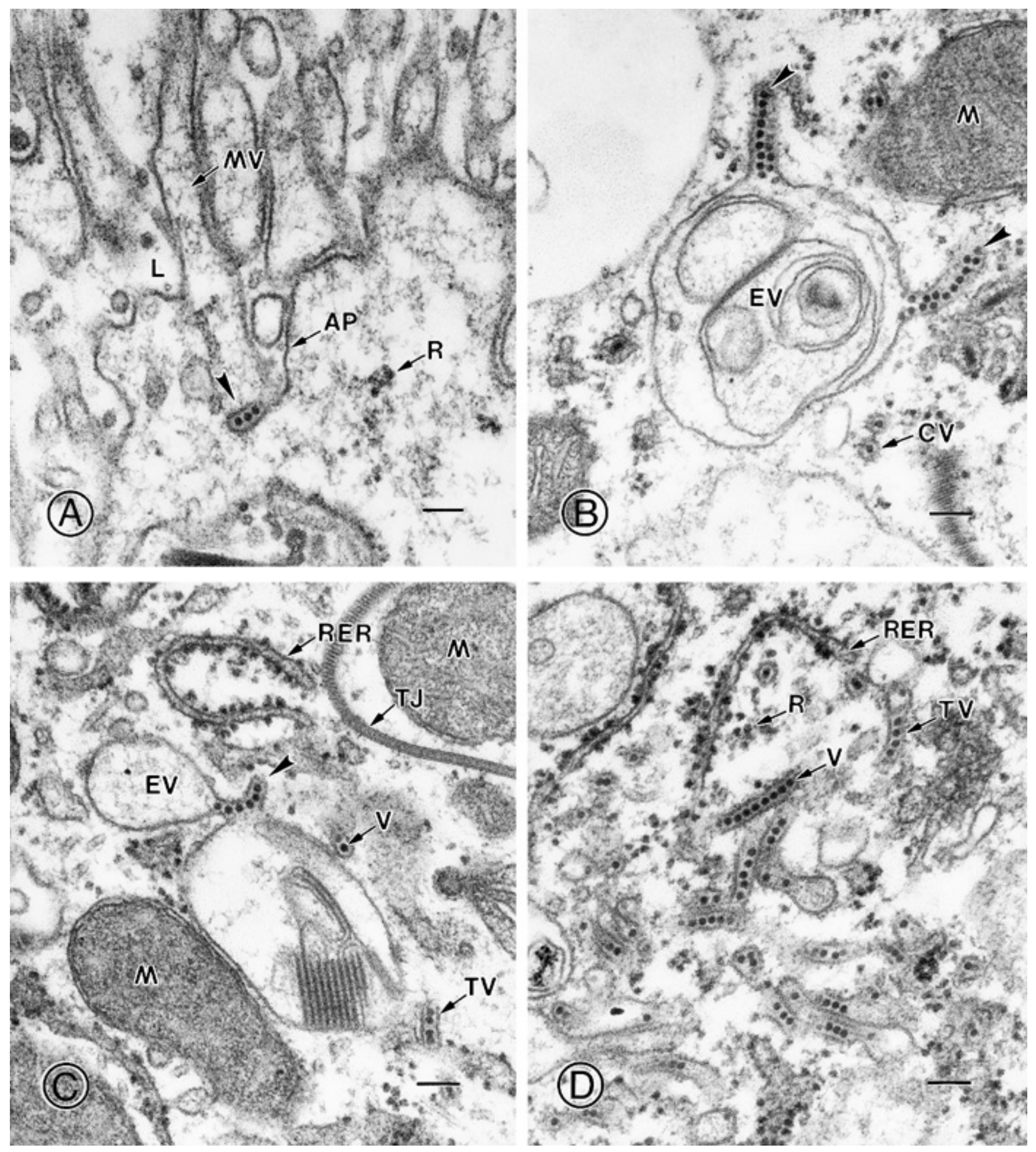

Fig. 3. Electron micrographs of sections through the posterior midgut of Myzus persicae showing stages of acquisition and transcellular transport of recombinant nucleocapsids following a 24-h membrane feeding on purified FL-VLP. A, Three nucleocapsid virus-like particles (VLP) in a coated-pit (arrow head) invaginating through the apical plasmalemma (AP) from the midgut lumen (L). B and C, Two views of linear arrays of VLP (arrow heads) located in developing tubular transport vesicles (TV) budding from endosomal vesicles (EV). Two VLP are observed in coated vesicles (CV) indicated by clathrin protein spikes. D, Comparison of tubular vesicles containing nucleocapsids (V) and rough endoplasmic reticulum (RER) coated with ribosomes located in the basal region of the midgut cell. Other structures: microvilli (MV), mitochondria $(\mathrm{M})$, ribosomes $(\mathrm{R})$, and tight junction $(\mathrm{TJ})$. Bar $=100 \mathrm{~nm}$. 
basal lamina from membrane-fed aphids in the same treatments (Table 1, Experiment 2).

All types of particles were readily observed at the accessory salivary gland in all aphids examined; VLP were observed in the same cellular locations as PLRV. In addition, VLP were frequently observed in the lumen of the salivary canal, which verified that the particles had been released from the salivary cell (Fig. 5C and D). In transmission tests, $P$. floridana seedlings did not become infected when fed on by aphids membrane-fed or microinjected with P3-6H VLP (Table1). The P3-6H VLP do not contain PLRV gene sequences and were not expected to be infectious. Seedlings were not infected when fed on by aphids that had acquired FL-
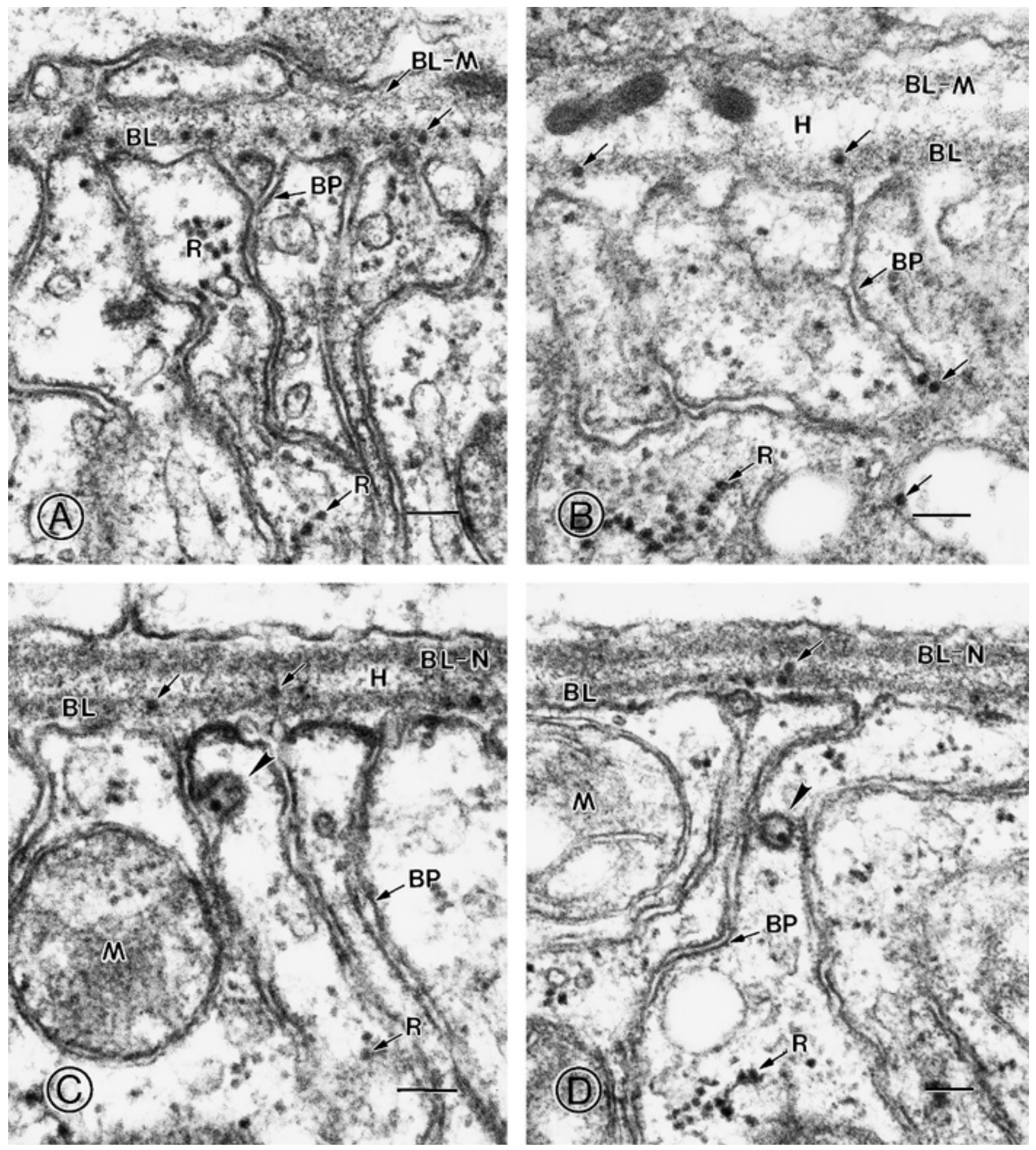

Fig. 4. Electron micrographs of sections through the accessory salivary gland (ASG) of Myzus persicae showing stages of basal lamina penetration and endocytosis of virus-like particles (VLP) $24 \mathrm{~h}$ following microinjection of purified P3-6H-VLP. A, VLP (unlabeled arrow) in various stages of penetrating through the ASG basal lamina (BL). Note specificity of VLP for the ASG basal lamina and the lack of VLP in the adjacent muscle cell basal lamina (BL-M). B, VLP (arrow) observed closely associated with the ASG basal plasmalemma (BP) in membrane cisternae and verifying penetration of the basal lamina. (C) Endocytosis of a VLP into a coated-pit (arrow head) on the ASG basal plasmalemma. Note the lack of VLP (arrows) in the basal lamina of the nerve cell (BL-N) adjacent to the ASG-BL. D, A later stage in endocytosis showing development of a coated-vesicle (arrow head) containing a virion from the basal plasmalemma. Other structures: ribosomes $(\mathrm{R})$, hemocoel $(\mathrm{H})$, and mitochondria $(\mathrm{M}) . \mathrm{Bar}=100 \mathrm{~nm}$. 
VLP containing PLRV-RNA, although particles were observed being released into the salivary canal. When PLRV and FL-VLP were used to inoculate tobacco protoplasts in two replicated treatments, PLRV particles infected the protoplasts (immunofluorescence positive; ELISA OD405 $=1.5$ ) the FL-VLP did not (immunofluorescence negative; ELISA OD405 $=0.15$, the back- ground value). These results and those of aphid transmission tests indicated that the FL-VLP were not infectious once inoculated into plant cells. Electrophoretic analysis of RNA extracted from purified particles indicated that the FL-RNA transcript encapsidated by the P3-6H capsid protein was approximately 400 nucleotides smaller than the genomic RNA isolated from PLRV-infected
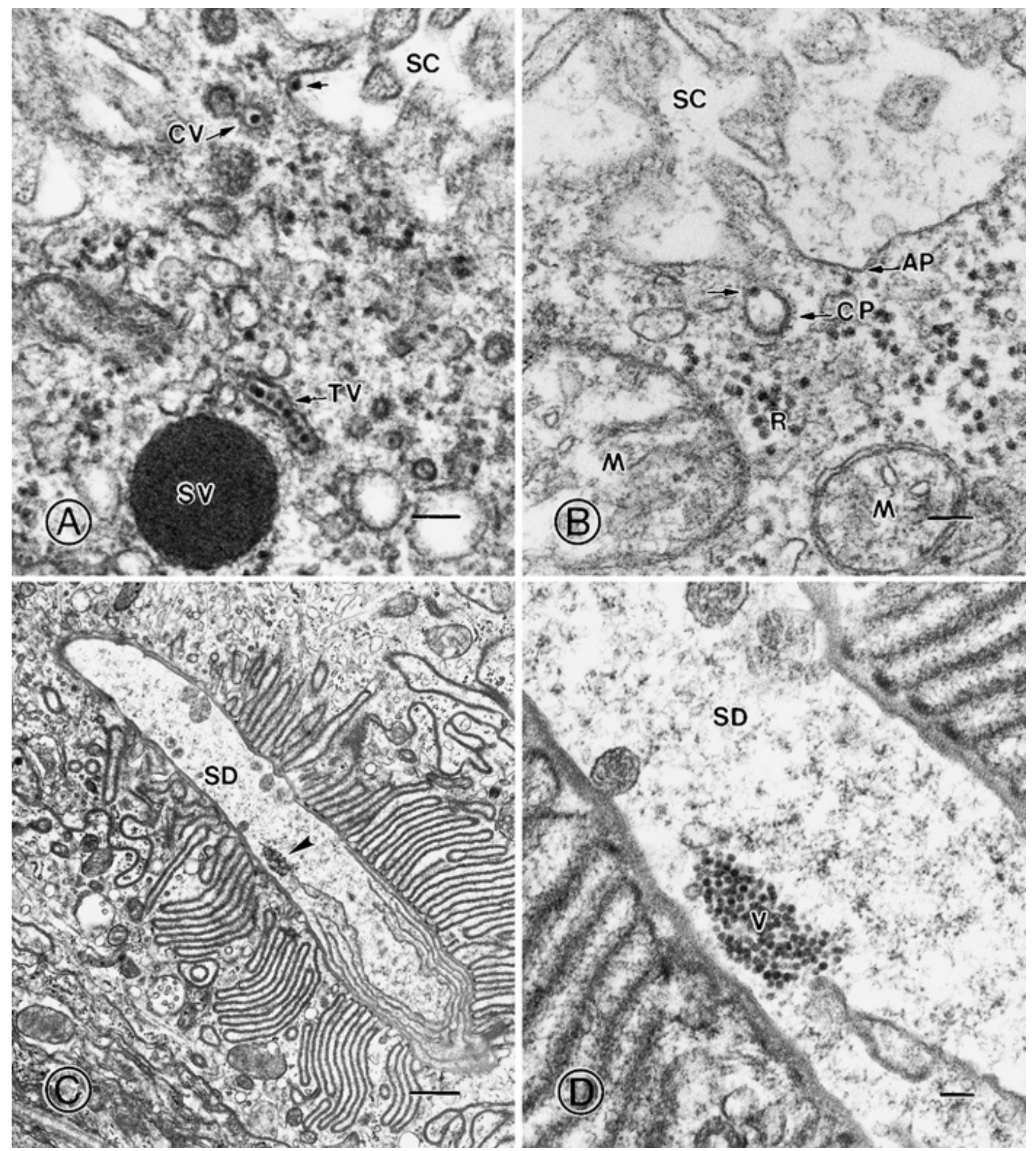

Fig. 5. Electron micrographs of the accessory salivary gland (ASG) of Myzus persicae $24 \mathrm{~h}$ after microinjection of A, C, and D, P3-6H-VLP or B, membrane feeding on FL-VLP purified preparations showing stages in exocytosis and transmission. A, A linear array of P3-6H particles in a tubular vesicle (TV), and a single particle in a coated-vesicle (CV) adjacent to the salivary canal (SC) and in the canal lumen (arrow) attached to the apical plasmalema following release from the cell. B, A single nucleocapsid of FL-VLP in a coated-pit (CP) opening into the salivary canal lumen. $\mathbf{C}$, Low magnification image of the chitin-lined salivary duct leading out of the ASG. Note accumulation of VLP (arrow head). D, High magnification of image $\mathbf{C}$, showing aggregation of P3-6H-VLP in the salivary duct following microinjection of anti-Potato leafroll virus IgG. Other structures: ribosomes $(\mathrm{R})$, mitochondria $(\mathrm{M})$, and secretory vesicles $(\mathrm{SV})$. Bar $=$ $100 \mathrm{~nm}$. 
plants (Fig. 1B). Although PLRV-FL RNA transcripts of $6 \mathrm{~kb}$ were observed in extracts from AcFL infected insect cells in small concentrations, these RNAs were not recovered from FL-VLP. Therefore, a critical portion of the PLRV genome was either not transcribed from the recombinant baculovirus (AcFL) or the FLRNA was truncated before or during packaging into the $\mathrm{P} 3-6 \mathrm{H}$ protein to form the FL-VLP.

\section{DISCUSSION}

No differences were observed among PLRV particles (with both P3 and P5 structural proteins) and two types of VLP (containing only modified P3) for their ability to be transported through the gut epithelium and accessory salivary glands of the aphid vector M. persicae. Our results suggest that the readthrough (P5) protein of PLRV is not essential for recognition and endocytosis of the virus into the gut or salivary gland or for site-directed transcellular transport through vector cell cytoplasm. These results are in agreement with previous studies suggesting that P5 is not required for aphid acquisition of luteovirus (3) and that sites important for virus recognition and transmission may occur on the P3 coat protein (26). Molecular genetic studies have indicated that luteovirus mutants lacking P5 protein are not transmitted by aphids $(2,3)$. These studies, however, did not differentiate between the ability of virions to circulate through the aphid and their ability to infect the host plant productively following aphid inoculation. Our study was directed at determining whether or not PLRV particles lacking P5 could circulate through tissues of the aphid vector in the same way that particles of PLRV could.

The mutant P5-minus particles were apparently stable in the hemocoel. Both types of VLP were observed in high concentrations embedded in the accessory salivary gland basal lamina $48 \mathrm{~h}$ after initiating acquisition by membrane feedings. Therefore, the absence of the P5 protein did not greatly affect the survival of particles in the hemocoel or their ability to penetrate the accessory salivary gland basal lamina, which has been shown to involve a specific recognition step for some luteoviruses $(12,21)$. Binding of Buchnera GroEL complexes to luteoviruses has been observed by EM in vitro studies (6). However, in this study, we saw no structural evidence of GroEL binding to either PLRV particles or to VLP.

The VLP produced in the recombinant baculovirus-lepidopteran cell system appeared structurally indistinguishable from PLRV in size, density, and serology. However, they were not infectious in plants because they contained no PLRV-RNA (P3-6H-VLP), or contained truncated noninfectious PLRV-RNA (FL-VLP). Both P3-H6-VLP and FL-VLP had similar capsids consisting of only the $\mathrm{P} 3$ coat protein modified by an additional 17 amino acid histidine-rich sequence on the $\mathrm{N}$ terminus. AcFL was transcribed in infected insect cells but neither P3 nor P5 were expressed and no VLP were formed. The absence of P3 and P5 in insect cells infected with AcFL is probably due to the PLRV subgenomic RNA not being produced in the cells. It therefore appears that either the replicase proteins encoded in the $5^{\prime}$ half of the PLRV genome are not synthesized in the AcFL-infected insect cells from the AcFLderived transcript or they are synthesized but not functional. This lack of functionality could be due to the absence of essential plant-derived cofactors or to structural alterations of the template PLRV-derived RNA. The FL-VLP containing the PLRV-specific RNA were formed only when cells were coinfected with Ac61. Therefore, both types of VLP would likely have appeared similar to the aphid vector cell membrane recognition systems during circulative transport through the aphid. The inability of $\mathrm{P} 3-6 \mathrm{H}$ and FL-VLPs to infect plants when inoculated by aphids verified that the particles observed moving through the midgut and accessory salivary gland by EM were recombinant VLP and not the result of contamination by PLRV. The P3-6H and FL-VLPs were positively identified in aphids by labeling in vivo with PLRV polyclonal antisera. Consistent results (Table 1) were obtained in three sepa- rate experiments with different virus and particle preparations, and two different clones of $M$. persicae over a 2-year period.

Based on our ultrastructural observations, we hypothesize that the P5 protein of luteoviruses may not be essential for virus transport through aphids. The route of PLRV-like particles lacking P5 was not different from that of the PLRV controls. Briefly, when acquired into the midgut lumen, both PLRV and VLP attached to the apical plasmalemma and were endocytosed into the gut epithelial cells. Coated vesicles transported particles to early or peripheral endosomes (20), which functioned to concentrate and repackage the particles into tubular transport vesicles. The tubular transport vesicles then delivered the particles to the basal plasmalemma and released the particles into the hemocoel by exocytosis. The particles remained stable while suspended in the hemolymph over a 48-h period. Particles contacting the accessory salivary gland bound to and penetrated the glycoprotein-rich basal lamina surrounding the salivary gland and became closely associated with the basal plasmalemma within membrane cisternae on the cell surface. Particles were then endocytosed, transported, and concentrated within tubular vesicles located at the apical end of the cell. Individual particles in coated vesicles budding from tubular vesicles were released from the salivary cell by exocytosis through the apical plasmalemma lining the salivary canal. The sequence of membrane-bound vesicle transport organelles utilized for virus acquisition at the gut appears to be the opposite of that used for transport through the salivary gland. How the addition of the N-terminal sequence of 17 amino acids on the P3 coat protein may have influenced particle recognition and survival in the aphid hemocoel is not known. However, particles did not assemble in the presence of unmodified P3 protein indicating that the additional sequence was essential for particle assembly. Assembly of modified $\mathrm{P} 3$ protein into particles could be explained by a number of possible mechanisms (14). Whether this hexahistidine tag on the P3 coat protein could mimic the function of P5 protein and influence particle surface morphology or charge is unknown at this time. In spite of these additional questions, our results indicated that the presence of the P5 readthrough protein was not absolutely essential for PLRV recognition and transport through aphid cell systems.

\section{ACKNOWLEDGMENTS}

We thank A. Jolly, G. Fraser, and J. Middlefell-Williams for technical assistance. Portions of this work done at SCRI were supported by The Scottish Office Agriculture, Environment and Fisheries Department, and Fulbright and Mylnefield Research Services Fellowships to F. E. Gildow. Work done at Pennsylvania State University was funded by National Science Foundation Grant MCB-9419807.

\section{LITERATURE CITED}

1. Bahner, I., Lamb, J., Mayo, M. A., and Hay, R. T. 1990. Expression of the genome of potato leafroll virus: Readthrough of the coat protein termination codon. J. Gen. Virology 71:2251-2256.

2. Brault, V., Van den Heuvel, J. M., Verbeek, M., Ziegler-Graf, V., Ruetenauer, A., Herrbach, E., Garaud, J. C., Guilley, H., Richards, K., and Jonard, G. 1995. Aphid transmission of beet western yellows luteovirus requires the minor capsid readthrough protein P74. EMBO J. 14:650-659.

3. Chay, C. A., Gunasinge, U. B., Dinesh-Kumar, S. P., Miller, W. A., and Gray, S. M. 1996. Aphid transmission and systemic plant infection determinants of barley yellow dwarf luteovirus-PAV are contained in the coat protein readthrough domain and $17-\mathrm{kDa}$ protein, respectively. Virology 219:57-65.

4. Cheng, S., Domier, L. L., and D'Arcy, C. J. 1994. Detection of the readthrough protein of barley yellow dwarf virus. Virology 202:1003-1006.

5. Filichkin, S. A., Lister, R. M., McGrath, P. F., and Young, M. J. 1994. In vivo expression and mutational analysis of the barley yellow dwarf virus readthrough gene. Virology 205:290-299.

6. Filichkin, S. A., Lister, R. M., McGrath, P. F., and Young, M. J. 1997. In vitro interactions of the aphid endosymbiotic SymL chaperonin with barley yellow dwarf virus. J. Virol. 71:569-577. 
7. Franco-Lara, L. F., McGeachy, K. D., Commandeur, U., Martin, R. R., Mayo, M. A., and Barker, H. 1999. Transformation of tobacco and potato with cDNA encoding the full-length genome of Potato leafroll virus: evidence for a novel virus distribution and host effects on virus multiplication. J. Gen. Virol. 80:2813-2822.

8. Garret, A., Kerlan, C., and Thomas, D. 1993. The intestine is a site of passage for potato leafroll virus from the gut lumen into the hemocoel in the aphid vector, Myzus persicae Sulz. Arch. Virology 131:377-392.

9. Gildow, F. E. 1982. Coated vesicle transport of luteovirus through the salivary gland of Myzus persicae. Phytopathology 72:1289-1296.

10. Gildow, F. E. 1993. Evidence for receptor-mediated endocytosis regulating luteovirus acquisition by aphids. Phytopathology 83:270-277.

11. Gildow, F. E., Damsteegt, V. D., Smith, O. P., and Gray, S. M. 1994. Cellular mechanisms regulating circulative transmission and aphid vector specificity of soybean dwarf luteoviruses. (Abstr.) Phytopathology 84(suppl.):S1155-1156.

12. Gildow, F. E., and Gray, S. 1993. The aphid salivary gland basal lamina as a selective barrier associated with vector-specific transmission of barley yellow dwarf luteovirus. Phytopathology 83:1293-1302.

13. Jolly, C. A., and Mayo, M. A. 1994. Changes in the amino acid sequence of the coat protein readthrough domain of potato leafroll luteovirus affect the formation of an epitope and aphid transmission. Virology 201:182-185.

14. Lamb, J. W., Duncan, G. H, Reavy, B., Gildow, F. E., Mayo, M. A., and Hay, R. T. 1996. Assembly of virus-like particles in insect cells infected with a baculovirus containing a modified coat protein gene of potato leafroll virus. J. Gen. Virol. 77:1349-1358.

15. Mayo, M. A., Robinson, D. J., Jolly, C. A., and Hyman, L. 1989. Nucleotide sequence of potato leafroll luteovirus RNA. J. Gen. Virol. 70:1037-1051.

16. Mayo, M. A., and Ziegler-Graff, V. 1996. Molecular biology of luteoviruses. Adv. Virus Res. 46:416-460.

17. McGrath, P. F., Lister, R. M., and Hunter, B. G. 1996. A domain of the readthrough protein of Barley yellow dwarf virus (NY-RPV isolate) is essential for aphid transmission. Eur. J. Plant Prot. 102:671-679.

18. Miller, J. S., and Mayo, M. A. 1991. The location of the $5^{\prime}$ end of the potato leafroll luteovirus subgenomic coat protein mRNA. J. Gen. Virol. 72:2633-2638.

19. Mohan, B. R., Dinesh-Kumar, S. P., and Miller, W. A. 1995. Genes and cis-acting sequences involved in replication of Barley yellow dwarf virus-PAV RNA. Virology 212:186-195.

20. Murphy, R. F. 1993. Models of endosome and lysosome traffic. Adv. Cell Mol. Biol. Mem. 1:1-17.
21. Peiffer, M. L., Gildow, F. E., and Gray, S. M. 1997. Two distinct mechanisms regulate luteovirus transmission efficiency and specificity at the aphid salivary gland. J. Gen. Virol. 78:495-503.

22. Reutenauer, A., Ziegler-Graff, V., Lot, H., Scheidecker, D., Guilley, H., Richards, K., and Jonard, G. 1993. Identification of beet Western yellows luteovirus genes implicated in viral replication and particle morphogenesis. Virology 195:692-699.

23. Roberts, I. M. 1986. Immunoelectron microscopy of extracts of virusinfected plants. Pages 293-357 in: Electron Microscopy of Proteins 5: Viral Topics. J. R. Harris and R. W. Horne, eds. Academic Press, New York.

24. Torrance, L. 1992. Analysis of epitopes on Potato leafroll virus capsid protein. Virology 191:485-489.

25. Van Den Heuvel, J. F. J. M., Bruyere, A., Hogenhout, S. A., ZieglerGraff, V., Brault, V., Verbeek, M., van der Wilk, F., and Richards, K. 1997. The N-terminal region of the luteovirus readthrough domain determines virus binding to Buchnera GroEL and is essential for virus persistence in the aphid. J. Virol. 71:7258-7265.

26. Van Den Heuvel, J. F. J. M., Verbeek, M., and Peters, D. 1994. The relationship between aphid-transmissibility of potato leafroll virus and surface epitopes of the viral capsid. Phytopathology 83:1125-1129.

27. Verwoerd, T. C., Dekker, B. M. M., and Hoekema, A. 1989. A small scale procedure for the rapid isolation of plant RNAs. Nucleic Acids Res. 17:2362.

28. Vincent, J. E., Lister, R. M., and Larkins, B. A. 1991. Nucleotide sequence analysis and genomic organization of the NY-RPV isolate of Barley yellow dwarf virus. J. Gen. Virol. 72:2347-2355.

29. Wang, J. Y., Chay, C. A., Gildow, F. E., and Gray, S. M. 1995. Readthrough protein associated with virions of barley yellow dwarf luteovirus and its potential role in regulating the efficiency of aphid transmission. Virology 206:954-962.

30. Waterhouse, P. M., Gildow, F. E., and Johnstone, G. R. 1987. Luteovirus group. No. 339 in: Descriptions of Plant Viruses. Commonw. Mycol. Inst./Assoc. Appl. Biol., Kew, England.

31. Waterhouse, P. M., Martin, R. R., and Gerlach, W. L. 1989. BYDVPAV virions contain readthrough protein. (Abstr.) Phytopathology 79(suppl.):S1215.

32. Watson, C. J., and Hay, R. T. 1990. Expression of adenovirus type 2 DNA polymerase in insect cells infected with a recombinant baculovirus. Nucleic Acids Res. 18:1167-1175.

33. Webster, K. D., and Barker, H. 1998. Detection and quantification of transcript RNA in transgenic plants using digoxigenin-labeled cDNA probes. Pages 437-445 in: Methods in Molecular Biology Vol. 20: Plant Virology. G. D. Foster and S. C. Taylor, eds. Humana Press, NJ. 